\title{
SKILLS AND COMPETENCIES IN MATHEMATICS OF ENGINEERING STUDENTS IN CONTEXT OF SUSTAINABLE DEVELOPMENT
}

\author{
Evija Kopeika $^{1}$, Liga Zvirgzdina ${ }^{2}$ \\ ${ }^{1}$ Riga Technical University, Latvia; ${ }^{2}$ Latvia University of Life Sciences and Technologies, Latvia \\ evija.kopeika@rtu.lv, liga.zvirgzdina@llu.lv
}

\begin{abstract}
High quality STEM (Science, Technology, Engineering and Mathematics) education, as well as education and training in general, contributes to sustained economic growth, as well as sustainable development by innovation, productivity and competitiveness. Increasingly, working with students highlights a problem that is growing every year, making it very difficult for students to study and understand the substance they are learning. A large percentage of students have poor school (primary, secondary) knowledge in exact subjects. That influences teacher's work as well. It is important to understand why such a situation has emerged and progresses. The authors of the article have conducted interviews for students of the two largest Latvia universities, -the Riga Technical University and the Latvia University of Life Sciences and Technologies, as well as for students from one of the most recognized college - the Riga Technical College. Several academic experts have been interviewed. The article reflects the results of a study on the level of knowledge of engineering program students in mathematics, when they start studies, as well as the growth of the level of knowledge in this field during studies. The article also reflects the results of a high-school math teacher interview; the article summarizes the results of the study, puts forward major challenges and offers solutions to problems.
\end{abstract}

Keywords: engineering education, mathematics, sustainable development, knowledge, application.

\section{Introduction}

Competing in the global, knowledge-based economy and adjusting to the digital age are long-term challenges Europe must continue to address. Investing in human capital is vital in meeting these challenges.

The Sustainable Development Goals (SDGs) were adopted by the United Nations General Assembly in September, 2015 as the Development Agenda to be achieved by the 2030. The SDGs are a set of global goals that provide a framework for shared action to be implemented by all countries and all stakeholders. According the Agenda, engineering is crucial in achieving sustainable development in every country. Technological progress is the foundation of efforts to achieve such objectives as increased resource and energy-efficiency. Without technology and innovation, industrialization will not happen, and without industrialization, development will not happen. Without engineering development will not happen, without mathematics engineering development will not happen.

Four years since the adoption of the Sustainable Development Goals, the 2019 Report notes progress in some areas, but global response has not been ambitious enough [1].

The majority of countries across Europe continue to face a low number of students interested in studying or pursuing a career in the STEM field. Demand for engineering professionals is significantly higher than supply. The majority of European countries, as well Latvia, consider STEM education a current priority and have or are developing strategies to improve teaching and learning and the uptake of studies and careers in this area.

The world is growing in research on how to better teach engineering and technology and how to build learning content in STEM, based on the idea of educating in four specific disciplines (STEM Science, Technology, Engineering and Mathematics). In order to improve the situation, the development of STEM education in most countries has been prioritized at least in one aspect as a national priority for the coming years. Develop new national strategies and initiatives, promote research-based learning and reform in STEM learning content. The Ministry of Economy has identified the main disproportions of the labour market for medium and long-term forecasts. It is noted that there is a large surplus of specialists in the fields of humanities and social sciences, and there remains a discrepancy between the supply of formal education and the demand of the labour market. Thus, demand for engineering professionals is significantly higher than supply [2-6].

An understanding of mathematics is central to a young person's preparedness for participation in and contribution to modern society. A growing proportion of problems and situations encountered in daily life, including in professional contexts, require some level of understanding of mathematics 
before they can be properly understood and addressed. Mathematics is a critical tool for young people as they confront a wide range of issues and challenges in the various aspects of their lives. OECD (Organisation for Economic Co-operation and Development) focus is mathematics with an additional test in creative thinking. The new PISA 2021 mathematics framework was recently launched. There is increased interest worldwide in what are called 21st Century skills and their possible inclusion in educational systems. The OECD has put out a publication that focuses on such skills and has sponsored a research project entitled The Future of Education and Skills: Education 2030. Some 25 countries are involved in this cross-national study of curriculum including the incorporation of such skills. The project has as its central focus what the curriculum might look like in the future, focusing initially on mathematics. Some of the key 21st Century skills are [7-8]:

- critical thinking;

- creativity;

- research and inquiry;

- self-direction, initiative and persistence;

- information use;

- systems thinking;

- communication and reflection.

PISA 2021 aims to consider mathematics in a rapidly changing world driven by new technologies and trends in which citizens are creative and engaged, making non-routine judgments for themselves and the society in which they live. This brings into focus the ability to reason mathematically, which has always been a part of the PISA framework. This technology change is also creating the need for students to understand those computational thinking concepts that are part of mathematical literacy. The competence of math is an individual's ability to think mathematically, articulate, apply and interpret math problems in different situations of life. It includes concepts, actions, facts and tools to describe, explain and predict different phenomena. The competence of math helps the individual recognize the role of math in life and make well-founded decisions that are necessary in the life of a constructive, interested and accountable 21st-century citizen [8].

The uncollected knowledge floor of a high-grade engineer in any field is the knowledge of the sciences. Which, as an essential value for human capital, is developed and accumulated from a year ago, starting from primary school age and even earlier.

For example, in order for an electrical and/or energy engineer to be able to develop efficient, economical and customer-friendly models for electrical circuits, he should be well acquainted with partial derivatives and differentials. To study the operation of different fields (such as a magnetic field), both their operating intervals and what to do to minimize them, you need to be familiar with both surface integrals and flow theory. There are a lot of such examples.

Many will say that there are serious computer programs for both design and calculation, such as AutoCAD, Mathcad, SolitWork and others, which can design and calculate everything that is needed, but without the understanding and ability of the author to base them, and at the same time forecast a number of project development scenarios from which one could choose the choice of the most appropriate projects to be developed or a set of estimates cannot be considered to be reliable.

The aim of the authors was to study the preparedness and attitude of students to mathematics as one of the cornerstones of engineering studies, in relation to the guidelines mentioned above.

\section{Materials and methods}

Teachers from two universities the Riga Technical University (RTU) and the Latvia University of Life Sciences and Technologies (LLU) and from the Riga Technical College (RTK) conducted a survey of engineering students. To better understand students' thoughts on one of the executed subjects - the role of mathematics in professional development was surveyed by first to fourth-year students. The survey involved 275 RTU students, 103 LLU students and 46 RTK students. The distribution of the survey participants by study year, the distribution of the survey participants by age and the overall quality of the basic math skills test assessments were determined in the study. 
The study clarified the role of mathematics in the education of young engineers in the context of the 21st-century basic skills. The relative links between the CE results [9] and the results of the first semester exam were identified. Ten, national-recognised, high-quality teachers were interviewed for a more effective study of the situation, a brief summary of the answers is provided in the article.

\section{Results and discussion}

The system of education in Latvia, including education in mathematics, at present is on a way to changes. Nowadays, young people often think that it is not so important to know how to perform mathematical calculations on paper, as there are many technologies developed, by help of which it is possible to do many things. They consider that computers will do everything instead of people and that it is not necessary to think about it [10].

Distribution of respondents depending on the higher education institution

Table 1

\begin{tabular}{|c|c|c|}
\hline Higher education institution & Absolute values & Percentage \\
\hline RTU & 275 & $65 \%$ \\
\hline LLU & 103 & $24 \%$ \\
\hline RTK & 46 & $11 \%$ \\
\hline Total & 423 & $100 \%$ \\
\hline
\end{tabular}

As it is increasingly difficult to prepare such qualified professionals in higher education, given that the level of training of young reflex students (students $1^{\text {st }}$ year of study) is becoming less and less mature, in addition, they lack an understanding of the role of expertise in the study process, not to mention their role in the development of logical thinking, the two universities RTU and LLU, and RTK teachers conducted a survey of engineering students (Table 1). Taking into account the number of new students of each training institution, such a distribution of the participants in the survey is significant and usable. In the analysis of the survey data, as well as analysis of variances and qualitative data, the authors of the article concluded that the differences between the learning institutions analysed were not statistically significant and therefore the responses of all students will be analysed together in the following text.

The distribution of students by study year and thus experience is summarized in Table 2 .

Table 2

Distribution of survey participants by study year and age

\begin{tabular}{|c|c|c|c|}
\hline Study year & Percentage & Age of students & Percentage \\
\hline The first & $55 \%$ & $18-25$ & $69 \%$ \\
\hline The second & $18 \%$ & $26-30$ & $16 \%$ \\
\hline The third & $21 \%$ & $31-40$ & $8 \%$ \\
\hline The fourth & $6 \%$ & $41-50$ & $7 \%$ \\
\hline
\end{tabular}

With each year, the average level of knowledge among young students is declining. It is originally possible to find out, when students begin their studies in the first year, by testing basic skills, by requiring them to complete the test. An overview of the test results is given in Figure 1.

As it can be seen in Figure 1, the share of outstanding ratings is not changing significantly, while the volume of mediocre valuations is declining, the volume of weak and very weak results is increasing.

Working in higher education, particularly with students from the first year of study, there is one very important obstacle: the poor basic skills of students in science subjects on primary and secondary subjects. Universities try to address this problem as far as possible. RTU organizes a 2 - point course in the first semester, - "Basic parts of elementary mathematics", which provides a revising of the most important topics of school mathematics, LLU offers weekend courses, while RTK offers additional teacher advice. These all processes, of course, improve the basic skills of students, but in the short term it is not possible to cover the volume of 12 years to be learned qualitatively. Such additional training at the beginning of studies is an additional burden for the young at a time when he needs to adapt to a new type of training and to the greater extent of topics to be taken. In addition, in the course 
of work, a large proportion of students demonstrate interest and diligence in the learning of topics. But the problems mostly arise, when the learning process needs to use skills and competencies that should be remembered from material and arithmetic learned at high school.

On the other hand, by studying intensively in higher education, spending much more time on topics than at high school, at primary school, regularly attending counselling, and using the option offered in upper schools, studying a repeat of high school topics in 2 weeks, not only the level of knowledge is improving rapidly, but the student's interest in this subject, particularly, the use of acquired knowledge is increasing.

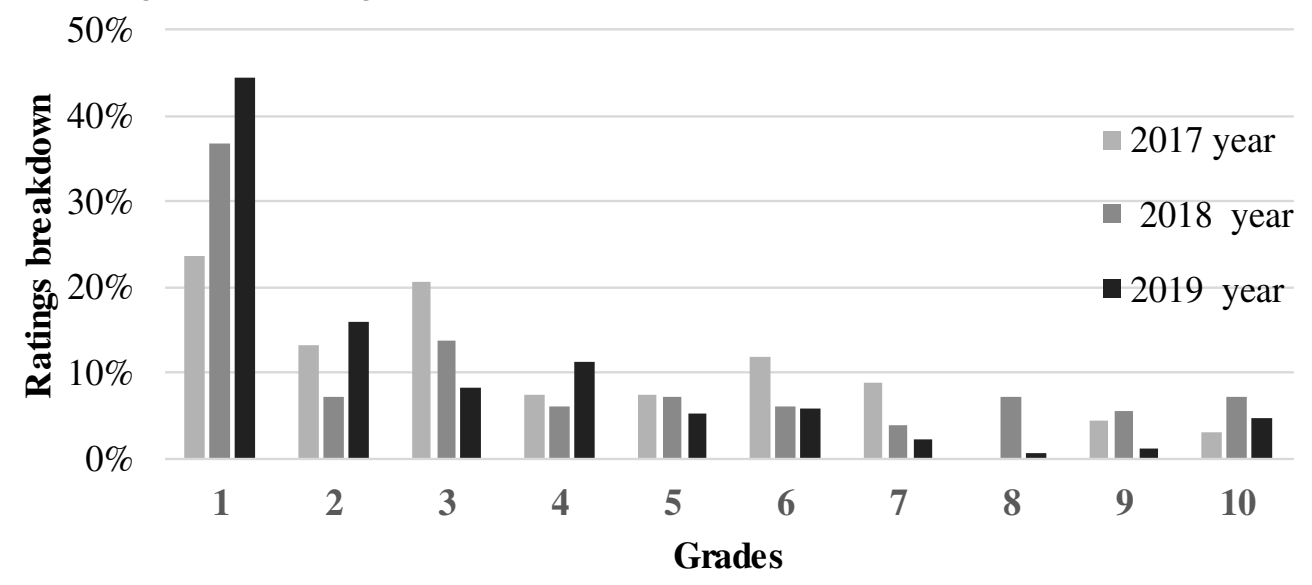

Fig. 1. Mathematics skills test summary 2017/18 until 2019/20 study years

Of course, some students, after the first lectures and tests, realize that they will not be able to meet the requirements they have set up, or decide that they do not want to invest so much in education and find other priorities, and leave their studies.

In view of this situation, the authors wanted to find out the reason why a large percentage of students have changed attitudes to math learning and aspiration so drastically during their studies. Assuming that the low results of the initial test are influenced by the fact that there are three months between the school exam and the university test, during which young people have rested and have given no special time for training, an analysis of the relationship between the results of the centralized exams (CE) and the results of the first semester was carried out, and in parallel between the results of the secondary study of the school teacher and the first study in the semester, the first results.

The results of the analysis are surprising: when checking the correlative link between the CE results and the results of the first semester it is very weak $\left(R^{2}=0.37\right.$, Sig $\left.=0.14\right)$, in addition, statistically insignificant with a probability of $95 \%$, and when assessing the likelihood of a second relationship, the relationship shown in formula 1 is obtained.

$$
Y=-1.67+1.02 X\left(R^{2}=0.72 ; \text { Sig. }=0.00\right)
$$

where $X$-assessment received at school;

$Y$ - results of the first semester.

Although the links are medium-strong, the relationship can be used. Although this model is simple and does not provide a full response to the student's expected results (because they are also influenced by many other factors, such as the student's involvement in studies), this indicates the importance of the relationship. So, at $95 \%$ confidence, this model represents $72 \%$ of the potential results. In addition, heteroscedasticity was tested, the results' safety assessment was carried out with both the graphical and Goldfeldt-Quandt test to check whether the variances of errors at each assessment were the same.

Using the Goldfeldt-Kvanda test, the calculated value $F_{\text {nov }}=0.97$, but $F$ critical value $F_{(175 ; 175 ; 0,05)}=1$. Since $F_{n o v}<F_{(175 ; 175 ; 0,05)}$, with $95 \%$ confidence there is no heteroscedasticity problem.

The results of both tests clearly indicate that there is no heteroscedasticity problem in this model. The presence of autocorrelation (i.e. errors correlate with each other) was also tested with the Durbin- 
Watson Test. In the given model $D W=1.81$ (value of d-statistics calculated by Durbin-Watson), taking into account the number of data (423) and the number of factors (1), theoretical values are obtained $d_{\text {Lower }}=1.77$, but $d_{U p p e r}=1.78$.

Since $d_{U p p e r}<D W<d_{4-U p p e r}$, with $95 \%$ confidence, autocorrelation does not exist, so errors do not correlate and there are no errors in the results.

Thus, using the parameter confidence interval at $95 \%$ level, with significance $72 \%$, on average we can say that, if a student has had grade 7 , the first-semester math grade in the higher educational institution will be between 4 and 6 (a direct forecast - grade 5).

There is an interest in finding out what the reason for such a result is. A more effective study of the situation has led to the recognition of high-quality secondary and primary school teachers in Latvia, a brief summary of which is provided in the article.

The problem appears that only short-term memory is developed. For example, 12 students have a quiz on a specific subject on 10 points (there are also tasks that are not shown above), but the CE cannot be performed by doing this type of task. The students cannot distinguish the method of resolving the task.

Fundamentally, the primary school math program should be reshaped so that students have a desire to learn, not to disgust them with the math. Learning the new substance should be seen in mediocrity, not by the best. Geometry should be taught in parallel to algebra, such as 4 hours of nonannual algebraic tasks and 2 hours of geometry, instead of 2 months counting and then a couple of weeks of geometry. It is very difficult and inefficient to work in classrooms, where there are over 25 pupils with different reception rates, initial knowledge and attitudes. It is very good to base training on skills without knowledge, but without basic skills and knowledge, there will also be no high-quality expertise. At high school, the number of hours is not sufficient to repeat the primary school substance and teach the basics themselves. A lot of hours are devoted to repeating an elementary school substance that pupils do not remember, which will reduce hours on new topics. But increasing the number of hours will not solve the problem, because students, and not only do believe that there is no need for knowledge of the mathematics, so other solutions are needed.

As no less important, it was pointed out that the fundamental problem starts in primary and secondary schools, where serious work is needed on the type and objectives of the programme and skills learning, in addition to having a student thoroughly mastered elementary-school math, he can complete the CE level, which is approaching the current moan level in the country, which indicates that at high school he can not to learn either.

Consequently, the minimum percentage for passing the $\mathrm{CE}$ must also be changed, since $5 \%$ on the ten-party scale is not even 1 party. Then there would be a chance for students to rely on luck and compose "both $5 \%$ will get" and not learn. Mathematics can best be learned by understanding the basic nature of topics and by addressing different tasks, both independently and in groups, and, when learning basic skills on a specific topic, devoting time to the application of a particular topic in practice, ideally, depending on the approach of the pupil (commercial, engineering and so on).

On the other hand, students in the survey indicate that when they are in higher education, the interest in math learning and understanding of relationships is increasing, indicating that from the first lesson, teachers explain what problems can be solved through specific methods, how to avoid mathematically intractable problems in studies, and what engineering projects are required and what is the role of the level of knowledge in the successful development of the project. Students also point out that the process of higher-grade teaching at high school is closely linked to both general education subjects (e.g. physics) and special courses (chain theory, signal theory, magnetism and others). Which is essential, students' assessment of the role of this knowledge in their professional growth is increasing gradually during education (see Figure 2).

As it can be seen in Figure 2, young people appreciate the role of mathematics knowledge in professional engineering studies, as well as working in their specialty, it is appreciated from $74 \%$ second year students to $96 \%$ last year students, to the question -"Do you need mathematics knowledge acquired in higher education in your professional subjects and in your specialty?", the answer is "yes", however completely reject the role of the mathematics from $0 \%$ last year students to $9 \%$ first year students to the same question answer "no". These results demonstrate the attitude of 
young specialists to math skills training, its role in professional growth, despite the obstacles, the desire to learn it as one of the cornerstones in their professional growth.

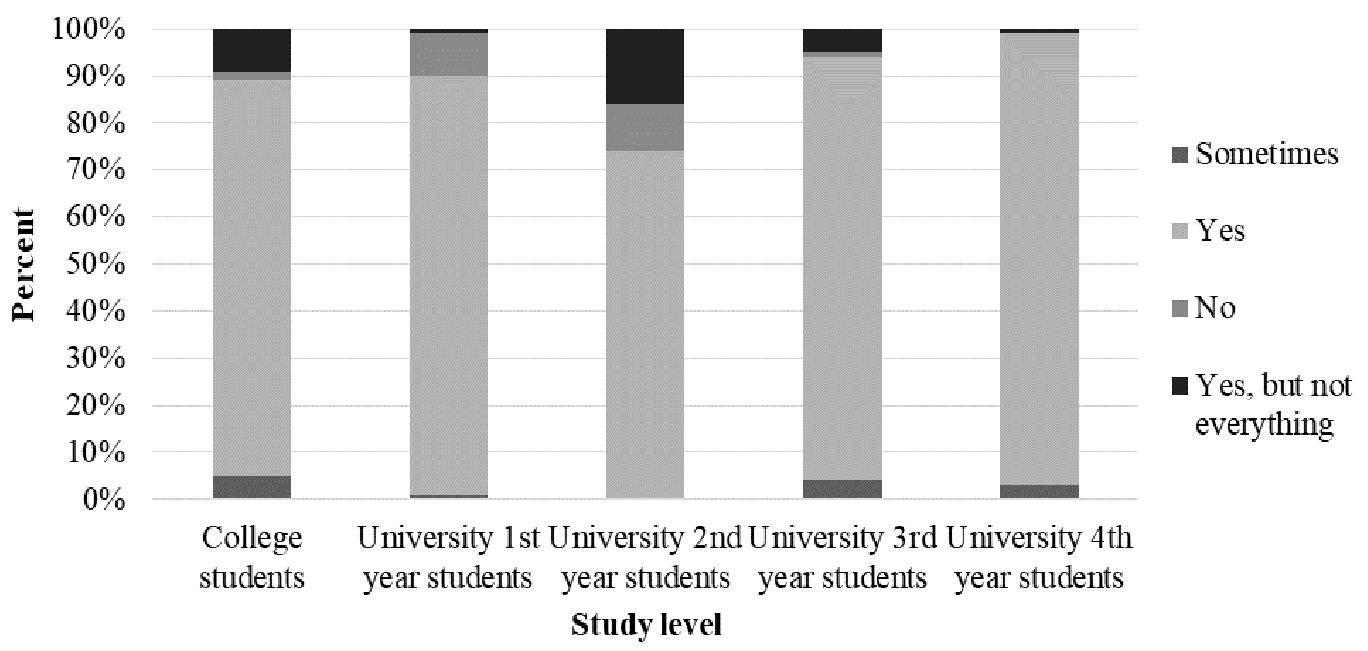

Fig. 2. Sudents answers to the survey question: "Do you need mathematics knowledge acquired in higher education in your professional subjects and in your specialty?"

The results have shown that, as technology develops, the role and assessment of math knowledge is with increasing tendency. For example, if we compare to a study carried out in 2017, analysis of the results among the clusters of specialties depicts that the highest appreciation of mathematical competences and their use is expressed by the students of electronics and energy (70\% on average). They have been able to precisely point out the areas in their specialty, where the mathematical knowledge obtained at university is crucial. They also stress that mathematical thinking that has been established at university and is still developing is a worthy "foundation stone" for their future career. Students connected with the specialties of economics also evaluate these competences rather high ( $68 \%$ on average), whereas the lowest evaluation for these competences is given by respondents, whose specialties are computer management and information technologies (43\% on average) $[11 ; 12]$.

\section{Conclusions}

1. The results of the survey have shown, as studies and practical experience grow, engineering specialist students increasingly recognise the importance of math skills.

2. The resulting relationship between the development of the level of knowledge in higher education and the grade in math is at a confidence level of $72 \%$, while there is no relationship with the CE, so that, in order to adequately assess future students and to divide potential budget places, greater emphasis should be placed on the assessment obtained at school, but ideally, examinations should be restored.

3. In the part of the study the self-assessment method has been used, so the results are based on respondents' views, and so the results cannot be generalized, but can be used to identify the problem and further explore it.

4. Mathematics curriculum should also focus on the mathematical competencies as outcomes besides the development of mathematical concepts and skills.

5. The authors have planned to continue their studies in this area through a dynamic analysis, as well as peer reviews between the Baltic and other European countries.

\section{Acknowledgements}

We thank the mathematics teachers at school for taking part in the interviews and the graduate students for actively completing the questionnaire.

\section{References}

[1] Sustainable Development Goals. [online] [18.04.2020]. Available at: https://www.un.org 
[2] Izvērtējums par profesijām atbilstošo prasmju saraksta izveidi. (Assessment of the establishment of a list of skills relevant to professions). (In Latvian) [online] [18.03.2020]. Available at: https://www.nva.gov.lv/docs/31_599570eb5343e6.41004842.pdf

[3] Izglîtīibas attīstības pamatnostādnes 2014.-2020.gadam. (Education Development Guidelines 2014-2020) (In Latvian) [online] [25.03.2020]. Available at: http://www.lsa.lv/wpcontent/uploads/2013/03/Izglitibasattistibaspamatnostadnes.pdf

[4] Darba tirgus vidēja un ilgtermiņa prognozes. (Medium and long-term forecasts for the labour market) (In Latvian) [online] [10.03.2020]. Available at: https://www.em.gov.lv/lv/aktuali/10556darba-tirgus-videja-un-ilgtermina-prognozes

[5] Valsts pārbaudes darbi (norises statistika un rezultātu raksturojums). (National examinations (performance statistics and performance characteristics)) (In Latvian) [online] [18.03.2020]. Available at: https://visc.gov.lv/vispizglitiba/eksameni/statistika.shtml

[6] One of opportunities to reduce student dropouts / Aivars Aboltins, Svetlana Atslega, Natalija Sergejeva, Liene Strupule. 18th International scientific conference "Engineering for Rural Development": proceedings, Jelgava, Latvia, May 22 - 24, 2019 [elektroniskais resurss] / Latvia University of Life Sciences and Technologies. Faculty of Engineering. - Jelgava, 2019. - Nr. 18, p. 1941-1946. - ISSN 1691-5976.

[7] PISA 2021 Mathematics Framework. [online] [18.03.2020]. Available at: https://pisa2021maths.oecd.org/

[8] PISA, Programme for International Student Assessment. [online] [18.03.2020]. Available at: https://www.oecd.org/pisa/

[9] Valsts izglìtības satura centrs. (National Centre for Education of the Republic of Latvia) (In Latvian) [online] [01.03.2020] Available at: https://visc.gov.lv/

[10] Sergejeva N., Aboltins A., Strupule L., Aboltina B. Mathematical knowledge in elementary school and for future engineers. 17th International scientific conference "Engineering for rural development": Proceedings, Jelgava, Latvia, May 23-25, 2018, pp. 1166-1172. [online] [25.03.2020] Available at: http://www.tf.llu.lv/conference/proceedings2018/Papers/N328.pdf

[11] Kopeika E. Mathematics as potential for the person's resilience. Proceedings of the 8th International Scientific Conference "Rural Development 2017", November 23-24, 2017, Vilnius, Lithuania, pp 6.

[12] Nahari N. Mathematical skills and attitudes of first year engineering students, Master theses, Dublin City University 2014, 110 p. [online] [30.04.2020] Available at: http://doras. dcu.ie/20200/1/ThesisNoha.pdf 